\title{
Confidential feedback workshops as a method to foster innovation
}

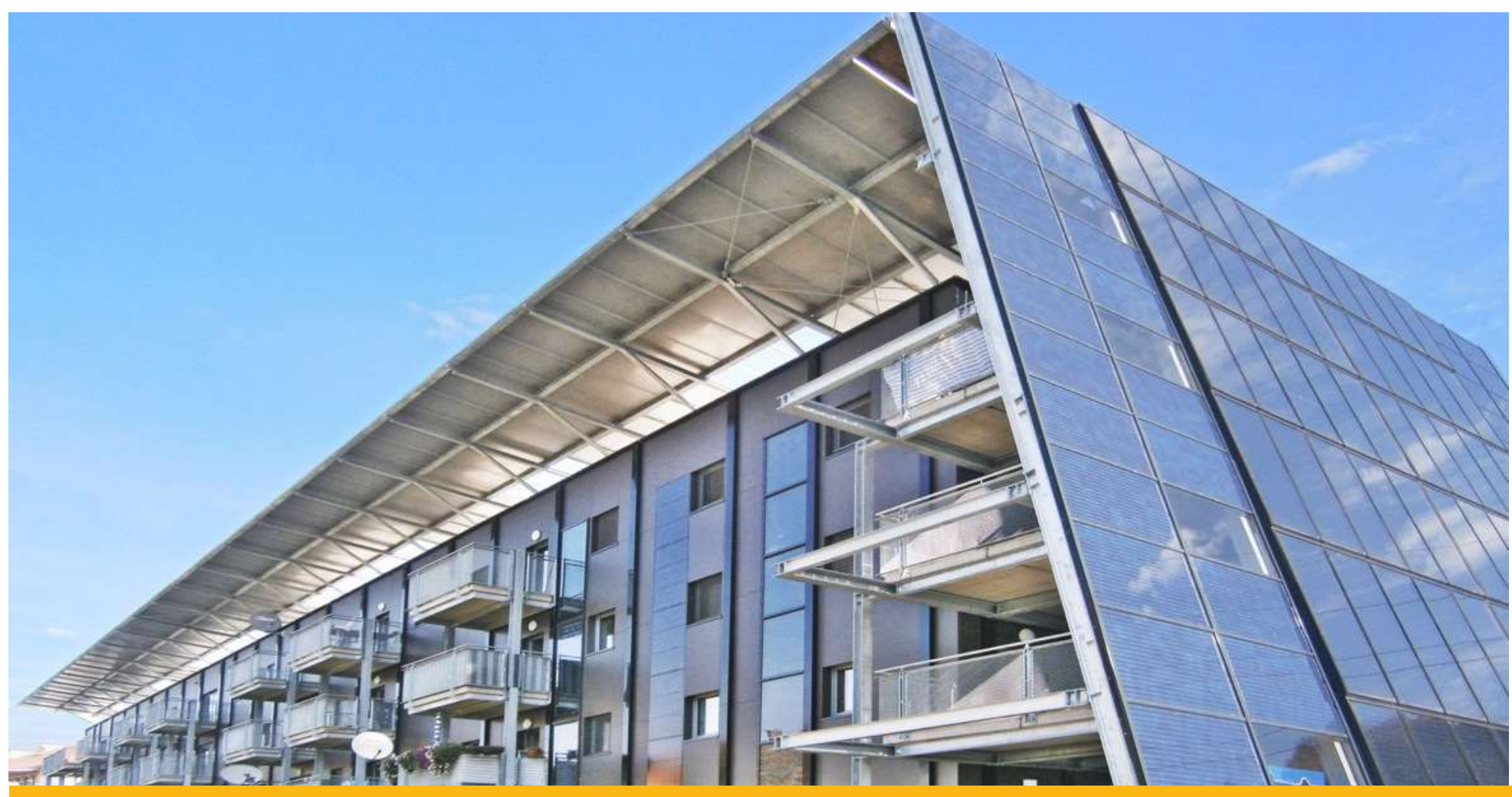

IEA SHC TASK 56 | Building Integrated Solar Envelope Systems for HVAC and Lighting 


\section{Report on confidential feedback workshops as a method to foster innovation}

Deliverable DB.3

Author: Christoph Maurer (Fraunhofer ISE)

December, 2019

DB.3, DOI: $10.18777 /$ ieashc-task56-2020-0002

The contents of this report do not necessarily reflect the viewpoints or policies of the International Energy Agency (IEA) or its member countries, the IEA Solar Heating and Cooling Technology Collaboration Programme (SHC TCP) members or the participating researchers. 


\section{IEA Solar Heating and Cooling Technology Collaboration Programme (IEA SHC)}

The Solar Heating and Cooling Technology Collaboration Programme was founded in 1977 as one of the first multilateral technology initiatives ("Implementing Agreements") of the International Energy Agency. Its mission is "To enhance collective knowledge and application of solar heating and cooling through international collaboration to reach the goal set in the vision of solar thermal energy meeting $50 \%$ of low temperature heating and cooling demand by 2050."

The members of the IEA SHC collaborate on projects (referred to as Tasks) in the field of research, development, demonstration (RD\&D), and test methods for solar thermal energy and solar buildings.

Research topics and the associated Tasks in parenthesis include:

- Solar Space Heating and Water Heating (Tasks 14, 19, 26, 44, 54)

- Solar Cooling (Tasks 25, 38, 48, 53)

- Solar Heat for Industrial or Agricultural Processes (Tasks 29, 33, 49, 62, 64)

- Solar District Heating (Tasks 7, 45, 55)

- Solar Buildings/Architecture/Urban Planning (Tasks 8, 11, 12, 13, 20, 22, 23, 28, 37, 40, 41, 47, 51, 52, 56, $59,63)$

- $\quad$ Solar Thermal \& PV (Tasks 16, 35, 60)

- Daylighting/Lighting (Tasks 21, 31, 50,61)

- Materials/Components for Solar Heating and Cooling (Tasks 2, 3, 6, 10, 18, 27, 39)

- $\quad$ Standards, Certification, and Test Methods (Tasks 14, 24, 34, 43, 57)

- $\quad$ Resource Assessment (Tasks 1, 4, 5, 9, 17, 36, 46)

- Storage of Solar Heat (Tasks 7, 32, 42, 58)

In addition to our Task work, other activities of the IEA SHC include our:

$>$ International Conference on Solar Heating and Cooling for Buildings and Industry

$>$ SHC Solar Academy

$>$ Solar Heat Worldwide annual statics report

$>$ Collaboration with solar thermal trade associations

\section{Country Members}

Australia

Austria

Belgium

Canada

China

Denmark

European Commission

\section{Sponsor Members}

European Copper Institute International Solar Energy Society

EACREEE

$\begin{array}{ll}\text { France } & \text { South Africa } \\ \text { Germany } & \text { Spain } \\ \text { Italy } & \text { Sweden } \\ \text { Netherlands } & \text { Switzerland } \\ \text { Norway } & \text { Turkey } \\ \text { Portugal } & \text { United Kingdom }\end{array}$

ECREEE

RCREEE

SACREEE

For more information on the IEA SHC work, including many free publications, please visit www.iea-shc.org 
Contents

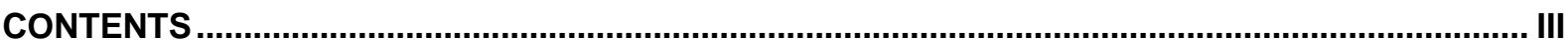

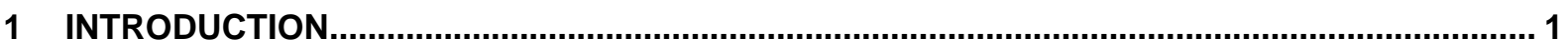

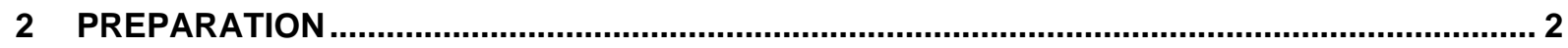

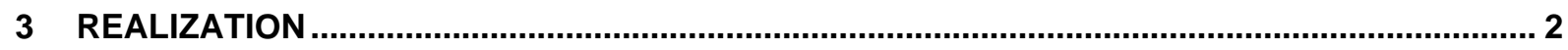

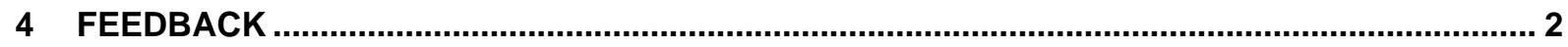

5 EXAMPLE

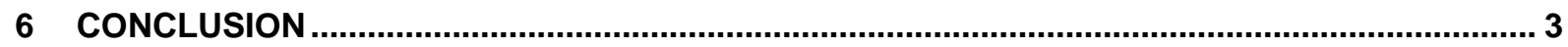

7 APPENDIX 


\section{Introduction}

Building Integrated Solar Envelope (BISE) technologies face a number barriers despite their potential (see Deliverable DB1 of the IEA SHC Task 56 for a detailed description of barriers). BISE technologies have a highly innovative character and often require that different professional disciplines interact closely in the manufacturing, installation and operation phases. For example, the implementation of solar thermal venetian blinds forces novel interactions between a façade manufacturer and a HVAC designer during the design and installation phases, which implies the need of new procedures and costs. The need to develop new know-how in a wide range of topics hinders the development of new technologies.

This deliverable proposes a new method aimed to mitigate this problem. The method is called Confidential Feedback Workshop and consists of providing a confidential forum for the fluent exchange of information among complementary actors related to BISE. Confidential Feedback Workshops have the potential to accelerate the process of acquiring the required know-how for a BISE technology to be marketable.

The participants of a confidential feedback workshop must fulfil at least two conditions to ensure the fluent exchange of information among them.

1. They must sign a confidential agreement.

2. They cannot be direct competitors.

In this deliverable, the basis of Confidential Feedback Workshops are presented. The method is exemplified by a first experience that took place on September 21, 2017, in Eindhoven, Netherlands. It was organized by the IEA SHC Task 56 on the topic solar building envelopes ${ }^{1}$. Confidential Feedback Workshops can also be used for other topics that require this transdisciplinary exchange.

\footnotetext{
1 Given the confidential nature of this type of workshops, this deliverable cannot release information about what was discussed during the Confidential Feedback Workshop in Eindhoven.
} 


\section{Preparation}

Like for any other workshop, the preparation of Confidential Feedback Workshops is crucial for its success. The organizer must select participants that are in the process of commercializing an innovation. The participants must be aware of the concept of the workshop and must see a benefit in participating in it. Under the conditions of confidentiality and no direct competition (see previous section), each participant must be willing to present the opportunities and challenges of commercializing his innovation in an understandable way to the other participants.

It is recommended to focus on participants who work close to the location of the workshop, or to attach the Confidential Feedback Workshop to a relevant conference. This limits the travel costs and still includes the view of people from other regions.

The organizer of a Confidential Feedback Workshop can be a start-up company or an organization that fosters innovations. If one start-up is very interested in the results, it could host it but needs an excellent network to find the right participants. Research Institutions are in many cases in a better position in order to increase the rate of successful start-ups.

The required non-disclosure agreement (NDA) must be highly reliable, short and easy to understand, for the participants to be able to process it without excessive effort from legal departments. The appendix includes the standard NDA of the Fraunhofer Institute.

\section{Realization}

It is usually a good idea to start a workshop with an "ice breaking" activity, which helps to relax and to establish first personal contacts among the participants of the workshop. Next, each participant will present his innovation, together with the opportunities and challenges for commercialization that he has already identified. The rest of participants will provide constructive feedback to the information presented, followed by a discussion, which might exceed the scope of the presented innovation.

The type of feedback that the presenting participant can receive from the other participants include the following (not extensive):

- Informed opinion about the marketing prospects of an innovation.

- Identification of problems which are not addressed sufficiently yet.

- Ideas on how to improve the commercialization of the innovation.

- Recommendations of possible business partners.

- Ideas for new innovations.

\section{Feedback}

In order to collect useful feedback from the participants of a workshop, it is recommended to give the participants the opportunity to lean back and reflect before they make a statement. A specific feedback section gives participants time to think, judge and formulate their feelings.

The simplest way to get qualitative good and honest feedback is, to hand out a short anonymous questionnaire with maximum four or five questions. It is usually a good strategy to ask first for the positive aspects of the feedback, because many people feel comfortable to criticize if they have already made some conciliatory statements. In this way, asking for feedback can be the last enjoyable exercise of the workshop. Asking the participants to re-image and relive the workshop help them to retain memories and reflections from the day. The feedback section closes by thanking the participants for their effort and engagement. 


\section{Example}

The first Confidential Feedback Workshop took place on the 21st of September, 2017, in Eindhoven, Netherlands. It was organized by IEA SHC Task 56 on the topic solar building envelopes. The following companies participated:

1. Bartenbach (Austria)

2. ElectricMondrian technology and Feedback (Netherlands)

3. Q-Roof (Netherlands)

4. BEAUsolar (Netherlands)

5. Fraunhofer ISE (Organizer)

Three of the four participants except of the moderator work in the same country in which the workshop took place. One participant arrived from another European country about $800 \mathrm{~km}$ away, but participated in another meeting right after the workshop.

\section{Conclusion}

This report presents the concept of Confidential Feedback Workshops, a method aimed to support innovations, especially for topics which require transdisciplinary exchange of information, like in the case of BISE technologies.

A Confidential Feedback Workshop has been first organized in Eindhoven, Netherlands. The participants evaluated the method very positively. The method was seen as a source of information that could not be reached by other means. Although the full potential is yet unknown, the current results indicate that Confidential Feedback workshops can be a valuable tool to increase the rate of successful start-ups.

However, this new method cannot be evaluated based on a single workshop. A systematic study is recommended to quantify the advantages and disadvantages, to judge in which cases it should be used and to optimize it regarding to the ratio of overall costs to participate and the benefits of participation. One challenge is that the concept of Confidential Feedback Workshops is still unknown, and participant cannot find any information online. This report will help to mitigate this problem. An article on Wikipedia would also make it easier to get informed quickly about the method. 


\section{Appendix}

Table 1 presents the invitation to the first CFW which was sent to possible participants together with a nondisclosure agreement which was prepared especially for CFW and is presented by Table 2 . The agenda of the first CFW is presented by Table 3 .

Table 1 Invitation to the first CFW

Subject: IEA Task 56 Confidential Feedback Workshop

Dear developer of an innovative solar building envelope,

it's my pleasure to invite you to a special event which may contribute to the success of your current developments.

As a participant, you present the technology which you are currently developing and you receive the feedback of international experts who are also active in developing innovations and who have a considerable experience with such developments.

The workshop will take place from 8:30 until 12:30 on 21.9.2017 in Eindhoven, Netherlands. After lunch, the meeting of the entire IEA Task 56 starts. For those you arrive on 20.9.2017, we plan to have dinner together at 19:00 o'clock. Please let me know if you like to join!

In order to be able to talk openly, also about details which are not yet published and new ideas, every participant needs to sign the attached nondisclosure agreement (NDA). It is based on the standard NDA of Fraunhofer which has been used for countless international cooperations. It allows you to use the feedback which you receive on your presentation to develop your technology. And it secures that the unpublished details of your technology stay within the group of the workshop participants. I attach the draft. Please send me the text which I shall fill for you and your company instead of the red place holders. If you have any questions about it, please let me know! When the participants are clear, I send around the final version for signing.

Please let me know as soon as possible if you plan to participate in this workshop, because the number of participants is limited.

Table 2 Non-disclosure agreement for the first CFW

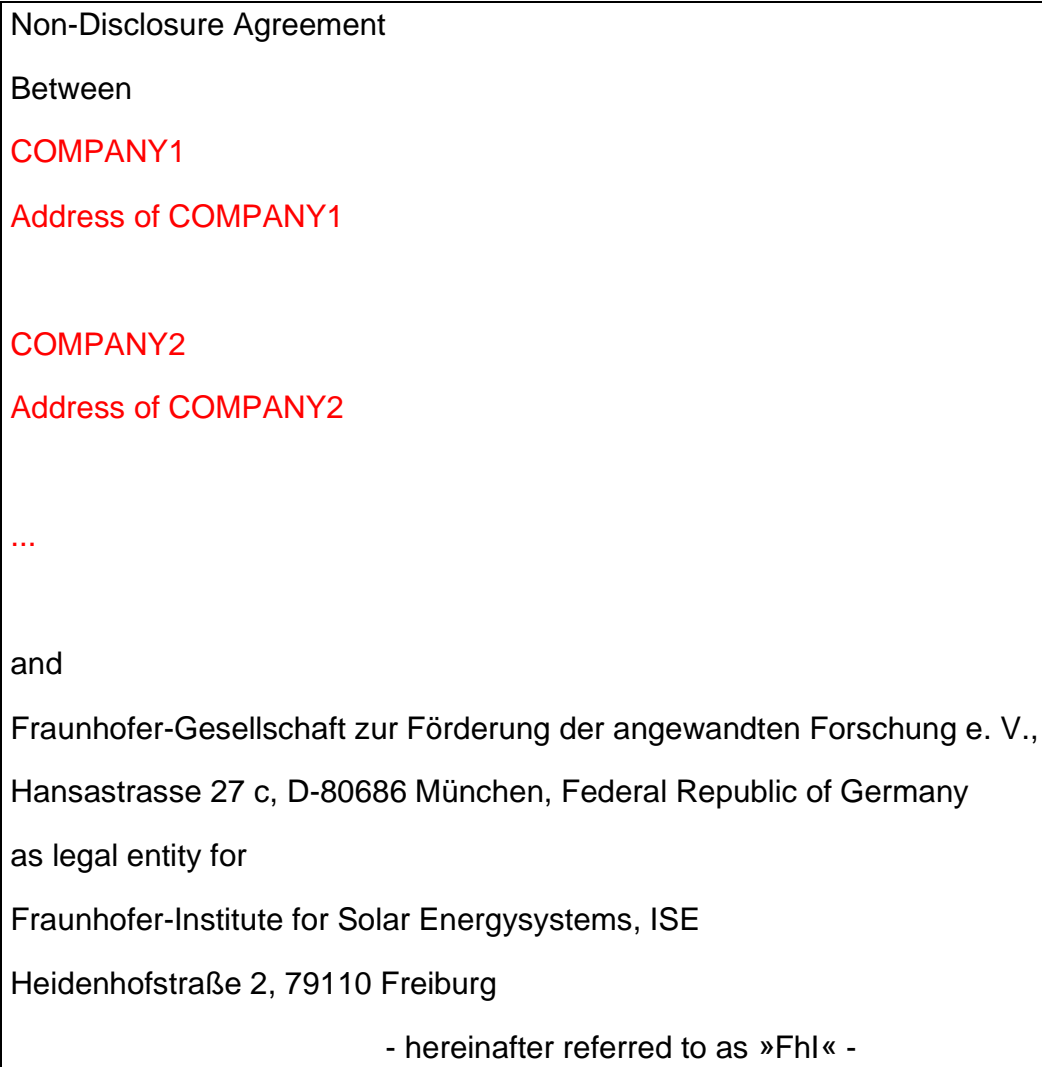


- $\quad$ hereinafter separately referred to as "Participant" and collectively referred to as "Participant" -

Whereas:

- $\quad$ The Participants

are taking part in the confidential feedback workshop of IEA SHC Task 56 on current developments of solar building envelopes on DATE OF THE CFW ("Workshop") organised and managed by Fhl. In the framework of the workshop the Participants intent to present their ongoing projects, the projects' objectives, the progress being made within these projects as well as the results being generated. In order to allow a frank and open exchange of informations the Participants hereby agree as follows:

1 For the purposes of this Agreement "Confidential Information « shall mean such technical and/or commercial information, including but not limited to any documents, drawings, sketches or designs, materials or samples disclosed by one of the Participants to another Participant or to the other Participants, and which at the time of its disclosure is identified as being confidential.

2 The Participants undertake to treat as confidential all and any Confidential Information and agree not to disclose the same to any third party except with the prior written consent of the disclosing Participant.

3 The restrictions on the use and disclosure of Confidential Information shall not apply to any information which is:

(a) proven to have been known to the receiving Participant prior to the time of its receipt pursuant to this Agreement; or

(b) in the public domain at the time of disclosure to the receiving Participant or thereafter enters the public domain without breach of the terms of this Agreement; or

(c) lawfully acquired by the receiving Participant from an independent source having a bona fide right to disclose the same; or

(d) independently developed by an employee of the receiving Participant who has not haccess to any of the Confidential Information of the disclosing Participant .

4 Relevant contact persons of each Participant:

- NAME OF EMPLOYER1 of COMPANY1

- NAME OF EMPLOYER2 of COMPANY2

$-\ldots$

- Christoph Maurer of Fhl

$5 \quad$ Unless it is necessary for the definition of the collaboration and provided that any copy of Confidential Information is distributed to the contact persons listed in Section 4 only the receiving Participant shall not, without the prior written consent of the disclosing Participant, copy or reproduce any document provided to the receiving Participant containing in whole or in part Confidential Information and any Participant receiving any such document shall return or destroy the same and any copies thereof on the supplying Participant's request but the latest until termination of this Agreement. This shall not apply to copies of the electronically exchanged Confidential Information made as a matter of routine information technology back-up and to Confidential Information or copies thereof which must be stored by the receiving Participant according to mandatory law.

$6 \quad$ All Confidential Information supplied pursuant to this Agreement shall remain the property of the disclosing Participant disclosing or supplying the same and no rights, including but not limited to the right to apply for industrial property rights, are granted to the other receiving Participant in the same. The Participants agree that any Confidential Information is made available "as is" and that no warranties are given or liabilities of any kind are assumed with respect to the quality of such Confidential Information, including, but not limited, to its fitness for the purpose, non-infringement of third party rights, accuracy, completeness or its correctness.

$7 \quad$ This Agreement shall come into force on the date of the last signature and shall have retroactive effect from DATE OF THE CFW. This Agreement shall thereafter be valid for 1 day. The obligation of confidentiality hereunder shall continue to be valid for a period of 5 years after the end of the term of this Agreement.

8 Ancillary agreements, amendments, additions hereto must be made in writing.

9 This Agreement is subject to and governed by the laws of the Federal Republic of Germany. 
10 If any provision of this Agreement is determined to be illegal or in conflict with the applicable law, the validity of the remaining provisions shall not be affected. The ineffective provision shall be replaced by an effective provision which is economically equivalent. The same shall apply in case of a gap.

\begin{tabular}{lll}
\hline Date & Location & \\
\hline Date & Location & Signature of COMPANY2 \\
$\ldots$ & \\
\hline Location & Signature of Christoph Maurer for Fhl \\
\hline
\end{tabular}

Table 3 Agenda of the first CFW

\section{AGENDA CONFIDENTIAL FEEDBACK WORKSHOP}

IEA SHC Task56 Subtask B

Christoph Maurer, https://s.fhg.de/profile-c-maurer

\author{
We meet at Room 6.06 \\ Eindhoven University of Technology \\ Het Kranenveld 8, \\ 5612 Eindhoven, the Netherlands \\ https://goo.gl/maps/BkPAE5U7A322
}

Thursday, 21.9.2017

\begin{tabular}{|c|c|c|c|c|}
\hline Start & End & Topic & Moderation & Duration \\
\hline $8: 45$ & $9: 00$ & Welcome coffee & Christoph Maurer & $00: 15$ \\
\hline 9:00 & $9: 25$ & Introduction & Christoph Maurer & $00: 25$ \\
\hline $9: 25$ & $9: 55$ & $\begin{array}{l}\text { Presentation of a Bartenbach technology and } \\
\text { Feedback }\end{array}$ & David Geisler-Moroder & $00: 30$ \\
\hline $9: 55$ & $10: 20$ & $\begin{array}{l}\text { Presentation of an ElectricMondrian technology and } \\
\text { Feedback }\end{array}$ & Wilfried van Sark & $00: 25$ \\
\hline $10: 20$ & $10: 45$ & Presentation of a Q-Roof technology and Feedback & Ruud Derks & $00: 25$ \\
\hline $10: 45$ & $11: 00$ & Coffee break & Christoph Maurer & $00: 15$ \\
\hline $11: 00$ & $11: 25$ & $\begin{array}{l}\text { Presentation of a BEAUsolar technology and } \\
\text { Feedback }\end{array}$ & Raoul Comuth & $00: 25$ \\
\hline $11: 25$ & $11: 50$ & $\begin{array}{l}\text { Presentation of a Fraunhofer ISE technology and } \\
\text { Feedback }\end{array}$ & Christoph Maurer & $00: 25$ \\
\hline $11: 50$ & $12: 45$ & $\begin{array}{l}\text { Discussion about topics which involve more than } \\
\text { one of the technologies and possible next steps }\end{array}$ & Christoph Maurer & $00: 55$ \\
\hline $12: 45$ & $12: 50$ & Summary & Christoph Maurer & $00: 05$ \\
\hline $13: 00$ & $14: 30$ & Lunch & Christoph Maurer & $01: 30$ \\
\hline
\end{tabular}


The workshop developed according to the agenda. At the end of the workshop, the participants assessed it positively as a "good concept", "helpful" and "productive". In order to further improve the concept, the participants were invited by email to criticize: "I got much positive feedback for the workshop, but you are very welcome to criticize since we need to decide if we should continue with similar workshops, maybe in an improved form." Each participant answered and Table 4 cites the answers.

\section{Table 4 The answers to asking the participants for possible improvements}

Thank you for organizing this workshop, I liked the concept very much.

Thank you for the workshop.

I think we agreed the workshop was VERY positive.

thanks again also from my side for the fruitful discussion!

Thank you for the workshop.

In the summary, you could be more positive.

I think we agreed the workshop was VERY positive. 